\title{
Hemoglobin A1C Percentage in Nonhuman Primates: A Useful Tool to Monitor Diabetes before and after Porcine Pancreatic Islet Xenotransplantation
}

\author{
Marco Marigliano, ${ }^{1,2}$ Anna Casu, ${ }^{1,3}$ Suzanne Bertera, ${ }^{1}$ Massimo Trucco, $^{1}$ and Rita Bottino ${ }^{1}$ \\ ${ }^{1}$ Division of Immunogenetics, Department of Pediatrics, Children's Hospital of Pittsburgh of UPMC, 4401 Penn Avenue, \\ Pittsburgh, PA 15224, USA \\ ${ }^{2}$ Regional Center of Pediatric Endocrinology and Diabetology, “G. Salesi” Hospital, Via Corridoni 11, 60121 Ancona, Italy \\ ${ }^{3}$ Diabetes Unit, Department of Medicine, Istituto Mediterraneo per i Trapianti e Terapie ad Alta Specializzazione (ISMETT), \\ Via Ernesto Tricomi, 190127 Palermo, Italy \\ Correspondence should be addressed to Rita Bottino, rib16@pitt.edu
}

Received 31 December 2010; Accepted 24 February 2011

Academic Editor: Diego Cantarovich

Copyright ( $) 2011$ Marco Marigliano et al. This is an open access article distributed under the Creative Commons Attribution License, which permits unrestricted use, distribution, and reproduction in any medium, provided the original work is properly cited.

\begin{abstract}
Non-human primates (NHPs) are a very valuable experimental model for diabetes research studies including experimental pancreatic islet transplantation. In particular NHPs are the recipients of choice to validate pigs as possible source of pancreatic islets. The aim of this study was to quantify glycated hemoglobin percentage in NHPs and to assess whether changes in values reflect the metabolic trends after diabetes induction and islet transplantation. Sera from 15 NHPs were analyzed. 9 NHPs were rendered diabetic with streptozotocin (STZ), and 3 of them received porcine islet transplants. Hemoglobin Alc (HbAlc) percentage was measured with an assay based on a latex immunoagglutination inhibition methodology. Whereas diabetes and its duration were associated with increasing HbAlc levels, postislet transplantation blood glucose normalization was paralleled by a decrease in the $\mathrm{HbAlc}$ percentage. Our data provide evidence that HbAlc is a useful tool to monitor glucose metabolism in NHPs.
\end{abstract}

\section{Introduction}

Nonhuman primates (NHPs) do not develop autoimmune diabetes. However a permanent type 1 diabetes-like status can be experimentally induced either by total pancreatectomy or by chemical destruction of pancreatic $\beta$-cells with streptozotocin (STZ) $[1,2]$. Both experimental approaches allow for the establishment of chronic hyperglycemia and low endogenous insulin production in NHPs, similarly to what it is found in humans with type1 diabetes. In patients an optimal treatment of diabetes involves control of glycemia by insulin administrations under haemoglobin A1c (HbAlc) monitoring [3]. Daily glucose measurements, even if frequent, do not provide accurate measures of longterm average blood glucose concentrations. The best method to assess long-term glycemic control is the measurement of $\mathrm{HbAlc}$ [4]. HbAlc values are important parameters for physicians and quite helpful to adjust the dose of insulin and antidiabetic drugs for a better control of the disease [5]. Evidence supporting the translation of HbA1c into glycemic control and long-term risk assessment of microvascular complications has been provided by the Diabetes Control and Complications Trial (DCCT) [3] and the United Kingdom Prospective Diabetes Study (UPKDS) [6]. The DCCT and the UKPDS are landmark clinical trials that compared the effect of intensive glucose-lowering therapies with conventional blood glucose control on the long-term risks of complications in patients with type 1 (DCCT) [3] and type 2 (UKPDS) [6] diabetes. Both of the trials documented that better glycemic control was associated with improved clinical outcome.

$\mathrm{HbAlc}$ values are strongly correlated with blood glucose levels and with the risk of developing complications. This is the reason why we thought it useful to record $\mathrm{HbAlc}$ 
as a parameter to monitor diabetes in NHPs (particularly in long-term islet graft recipients) as in humans [3]. Even if species differences should be taken into consideration, testing of novel therapeutic approaches in NHPs is one of the best ways to predict possible effects in humans. Clinical signs vary, but there is often a gradual progression of the disease even in NHPs. Traditional tests for the detection of diabetes mellitus include measurement of fasting plasma glucose concentrations, measurement of urine glucose concentrations, oral (OGTT) and IV (IVGTT) glucose tolerance tests, measurement of urine ketone concentrations, and measurement of fasting plasma insulin concentrations [7-11]. Diagnostic criteria are ideally based on the risk of developing long-term microvascular complications [11-14]. While NHPs are the recipients of choice for testing alternative sources of pancreatic islets, such tests present challenges in these animals. These include difficulty in sample collection, necessity for anesthesia during blood drawing with the potential for drug interactions, multiple confounding factors (e.g., activity, duration of food withholding, or diet), stress hyperglycemia attributable to restraint (i.e., catecholamine release suppressing insulin secretion), and lack of established reference ranges [15-17].

Objectives of the study reported here were to identify values for measurement of HbAlc percentage in blood samples obtained from NHPs (Macaca fascicularis) to determine whether these percentages varied with respect to glycemic control after diabetes induction and insulin treatment. HbAlc measurements were also carried out after pig islet transplantation in diabetic NHP recipients in an attempt to assess whether this physiologic variable can be considered a suitable test to monitor glucose metabolism and provide a positive feedback after islet transplantation, particularly in long-term survivors. Even if islet xenotransplantation of porcine islets in NHPs restores normal blood glucose levels in diabetic recipients, to date no clear long-term effect has been fully demonstrated. Glycated hemoglobin percentage can offer a reliable means to determine the establishment of euglycemia after xenotransplantation.

\section{Materials and Methods}

2.1. Animals. A total of 15 male Cynomolgus monkeys (i.e., Macaca fascicularis, Three Spring Scientific, Perkaise, PA, USA), 2-4 years old and $2.8-4.9 \mathrm{~kg}$ (median $3.4 \mathrm{~kg}$ ), were included in this study; 6 monkeys were nondiabetic, 9 diabetic, and 3 diabetics received islet transplantations. Catheters were placed into the jugular vein and carotid artery. GT-DKO pigs ( $\alpha$-1,3-galactosyltransferase double KO pigs) or hCD46 transgenic pigs (Revivicor, Blacksburg, VA, USA) were used as sources of pancreata for islet transplantation. All animal care procedures were in accordance with the institutional Principles of Laboratory Animal Care (National Society for Medical Research) and the Guide for the Care and Use of Laboratory Animals and were approved by the University of Pittsburgh Animal Care and Use Committee.

2.2. Induction of Diabetes. Diabetes was inducted in 9 monkeys with 125-150 mg/kg i.v. of Zanosar Streptozotocin
(Sicor Pharmaceutics, Irvine, CA, USA) in a single dose [1]. Diabetes was confirmed by persistent hyperglycemia ( $>11.1 \mathrm{mmol} / \mathrm{L}$ on at least two consecutive readings) and by the need for insulin to prevent ketosis [12]. IVGTTs (intravenous glucose tolerance test) and ASTs (arginine stimulation test) were performed 7-31 days (median 12 days) after induction of diabetes. Diabetic monkeys were treated by continuous i.v. infusion of insulin (Humulin R; Eli Lilly, Indianapolis, IN, USA) to maintain the blood glucose level $<11.1 \mathrm{mmol} / \mathrm{L}$ and to prevent the development of ketosis. Insulin therapy was stopped $1.5 \mathrm{~h}$ before stimulation tests.

2.3. Metabolic Parameters. Blood glucose (mmol/L) was measured in whole blood with a portable glucometer (Freestyle; Abbott Laboratories, Abbott Park, IL, USA). Serum levels of primate C-peptide $(\mathrm{nmol} / \mathrm{L})$ were measured by radioimmunoassay (Linco Research, St Charles, MO, USA) using species-specific antibodies. Aprotinin $0.05 \mathrm{kIU} / \mathrm{l}$ (Trasylol; Bayer Pharmaceuticals, West Haven, CT, USA) was added to the serum as a stabilizing agent. To document the metabolic status of each monkey before induction of diabetes, after induction of diabetes, and after islet transplantation until euthanasia, we recorded mean blood glucose $(\mathrm{mmol} / \mathrm{L})$, the prevalence of blood glucose readings $>11.1 \mathrm{mmol} / \mathrm{L}$ (\%), the mean exogenous insulin requirement $\left(\mathrm{IU} \mathrm{kg}{ }^{-1} \mathrm{day}^{-1}\right.$ ), and mean porcine (graft) C-peptide levels [18].

Blood samples for HbA1c testing were collected fasting every 2-4 weeks before and after induction of diabetes. Immediately after collection of a sample, blood was transferred into a tube containing EDTA, which was immediately used for measurement of HbAlc percentages. For the measurement of specific HbAlc, an inhibition of latex agglutination assay is used (HbAlc-specific mouse monoclonal antibody adsorbent onto latex particles, DCA Vantage Analyzer, Siemens Healthcare Diagnostics, Deerfield, IL, USA). An agglutinator (synthetic polymer containing multiple copies of the immunoreactive portion of HbA1c) causes agglutination of latex coated with HbAlc specific mouse monoclonal antibody. This agglutination reaction causes increased scattering of light, which is measured as an increased absorbance at $531 \mathrm{~nm}$. HbAlc in whole blood specimens competes for the limited number of antibodylatex binding sites causing an inhibition of agglutination and decreased scattering of light. The decreased scattering is measured as a decrease absorbance at $531 \mathrm{~nm}$. The HbAlc concentration is then quantified using a calibration curve of absorbance versus $\mathrm{HbAlc}$ concentration. The percent $\mathrm{HbA1c}$ in the sample is then calculated as follows: \%HbA1c $=[$ HbAlc $] /[$ Total Hemoglobin $] \times 100$.

2.4. Porcine Islet Isolation and Transplantation into Monkeys. After pancreatectomy in the anesthetized donor pig, islet isolation was carried out according to a modification of the method described for human islets, optimized for pigs [19] that involved low enzyme concentration, low digestion temperature, and minimal mechanical digestion. Intraportal injection of islets (an average of 40,000100,000 islet equivalents/kg body weight) was carried out 
TABLE 1: Fasting blood glucose, C-peptide and HbA1c in monkeys and humans.

\begin{tabular}{lcr}
\hline & Cynomolgus monkeys & Humans \\
\hline Blood Glucose $(\mathrm{mmol} / \mathrm{l})$ & $3.1-4.9(3.7 \pm 0.1, n=31)^{\mathrm{a}}$ & $3.9-5.6[21]$ \\
C-peptide (nmol/l) & $0.47-2.93(1.40 \pm 0.17, n=18)^{\mathrm{a}}$ & $0.17-0.66[20]$ \\
HbAlc $(\%)$ & $3.5-5.0(4.4 \pm 0.1, n=23)^{\mathrm{a}}$ & $4.46-5.52[22]$ \\
\hline
\end{tabular}

Data are ranges, with means \pm SE and number of measurements in parameters. Human data were obtained from the literature and were measured in venous plasma [20-22]. Blood glucose levels are significantly lower in monkeys than in humans. C-peptide levels are significantly higher in monkeys. There is statistically difference regarding HbAlc levels. (Monkeys versus humans, ${ }^{a} \mathrm{P}<.05$ ).

under general anesthesia of recipients. Continuous insulin infusion was restored if blood glucose was consistently $>11.1 \mathrm{mmol} / \mathrm{L}$. After induction with antithymocyte globulin, immunosuppression was maintained with humanized antiCD154 monoclonal antibody (ABI 793, Novartis Pharma, Basel, Switzerland) and mycophenolate mofetil (Roche, Nutley, NJ, USA) [18].

Anticoagulation/antiaggregation/anti-inflammatory treatment was achieved with heparin or dextran sulfate, prostacyclin (GlaxoSmithKline, Research Triangle Park, NC, USA) and aspirin [18]; islet graft function was monitored by measuring porcine $\mathrm{C}$-peptide.

2.5. Statistical Analysis. A commercially available technical computing program was used for graphic analyses (GraphPad Prism 4 for Macintosh GraphPad Software, La Jolla, CA, USA). Suggested criteria for diabetic classification of subjects were derived from other studies $[7,15]$ that involved the use of NHPs. A commercially available statistical program was used for statistical analyses (GraphPad Prism 4 for Macintosh, GraphPad Software). Experimental data are presented as means \pm SE. Human data obtained from the literature are presented as the range of values or mean of the published data $[20,21]$.

\section{Results}

3.1. Comparison of Metabolic Parameters between Nondiabetic NHPs and Humans. Fasting HbAlc values measured in nondiabetic monkeys are presented in Table 1. The data for healthy monkeys were compared with the human data from the literature to better characterize similarities and differences, even though the comparisons are limited by the difference in the testing conditions. For a better characterization of differences between monkeys and humans Table 1 also reports fasting blood glucose and C-peptide levels comparisons, based on previous reports [18]. Blood glucose in fasting nondiabetic monkeys ranged from 3.1 to $4.9 \mathrm{mmol} / \mathrm{l}$ and was significantly lower than the corresponding values in humans [21] (3.9-5.6 mmol/l; $P<.05)$. Human C-peptide [20] values were consistently lower than monkey C-peptide levels $(0.47 \pm 2.93 \mathrm{nmol} / \mathrm{l}$ in monkeys versus 0.17 $0.66 \mathrm{nmol} / 1$ in humans, $P<.05)$. Furthermore, HbAlc values for nondiabetic healthy monkeys were lower than those in humans [22], with statistically significant difference (4.4 \pm $0.1 \%$ in monkeys versus $4.99 \pm 0.1 \%$ in humans, $P<.05)$.

3.2. Comparison of Metabolic Parameters between Nondiabetic and Diabetic NHPs. The HbAlc of nondiabetic monkeys was compared to that of monkeys that were streptozotocin (STZ) induced, hyperglycemic, and insulin independent. The increase in HbAlc levels following diabetes induction confirms also in NHPs the notion that chronically high blood glucose affects glycation of hemoglobin (Figure 1(a), $P<$ $.05)$. The diabetic status was characterized using standard metabolic tests. IVGTT and AST were performed in diabetic NHPs and compared to nondiabetic controls. As expected, during the IVGTT the peak of glucose concentration in diabetic monkeys was significantly higher $(P<.05,2 \mathrm{~min}$ after glucose i.v. infusion) than in nondiabetic monkeys (Figure 1(b)). Thereafter, the glucose levels decreased at a slower rate in diabetic than nondiabetic animals, as shown by the lower $K_{G}$ (mean $1.44 \pm 0.2 \mathrm{mmol}^{-1} \mathrm{~min}^{-1}, P<.001$ ). The C-peptide increase, seen in nondiabetic monkeys, was absent in diabetic monkeys (Figure 1(c)).

During the AST in nondiabetic monkeys (Figures $1(\mathrm{~d})$ and $1(\mathrm{e})$ ), blood glucose remained stable while C-peptide values rose at $2 \mathrm{~min}$ and then returned at prestimulus value at 5 minutes. The $\mathrm{ACR}_{\text {Arg }}$ ranged from 0.04 to $1.09 \mathrm{nmol} / \mathrm{L}$. Published data show that human $\mathrm{ACR}_{\mathrm{Arg}}$ is similar to that in monkeys; however, the absolute basal and stimulated values are lower in humans than in monkeys (22-23). In diabetic monkeys during the AST, blood glucose remained stable at approximately $10.8 \mathrm{mmol} / \mathrm{L}$, and C-peptide showed no response $\left(\mathrm{ARC}_{\mathrm{Arg}}-0.40-0.31 \mathrm{nmol} / \mathrm{L}\right)$. In summary, after STZ treatment, blood glucose levels in monkeys increased above $10 \mathrm{mmol} / \mathrm{L}$, and fasting levels of endogenous Cpeptide declined to values corresponding to $12-18 \%$ of the C-peptide levels before diabetes induction. Insulin was needed to maintain blood glucose $<11.0 \mathrm{mmol} / \mathrm{L}$ and to prevent ketosis. Any residual endogenous C-peptide did not respond to physiological stimuli, as shown by the results of the dynamic tests and by the absence of a correlation between endogenous C-peptide and blood glucose levels.

\subsection{Comparison of Metabolic Parameters in Diabetic NHPs} before and after Porcine Islet Transplantation. Figure 2 compares the blood glucose profile and HbAlc levels in two NHPs, during their followup after STZ and (in one case) islet transplantation. Figure 2(a) shows the blood glucose levels trend after STZ of monkey M124-08. Despite IV insulin treatment blood glucose level tended to increase, and coherently HbAlc values (red dots) also tended to increase (from a basal pre-STZ value of $4.3 \%$ to $8.2 \%$ at the end of followup). Figure 2(b) shows a second monkey (M12308) blood glucose profile and HbAlc values prior to and after islet transplantation. Whereas blood glucose control 


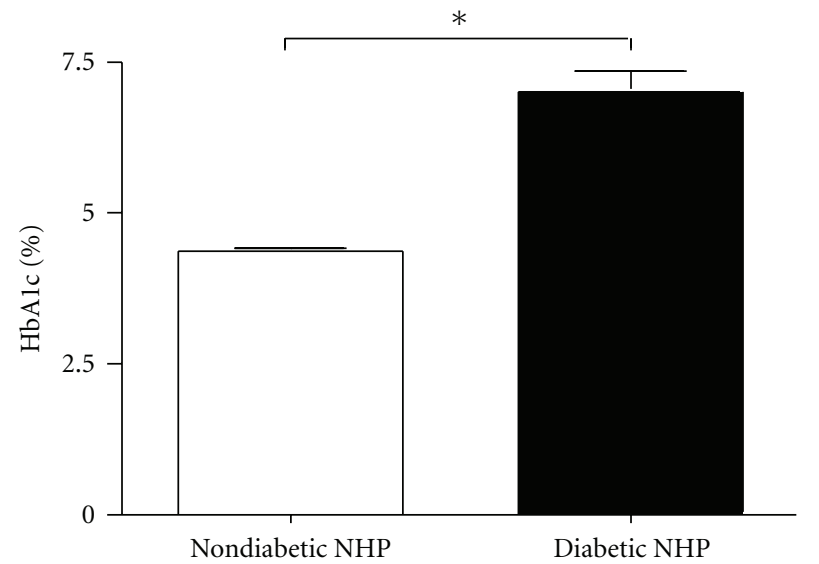

(a)

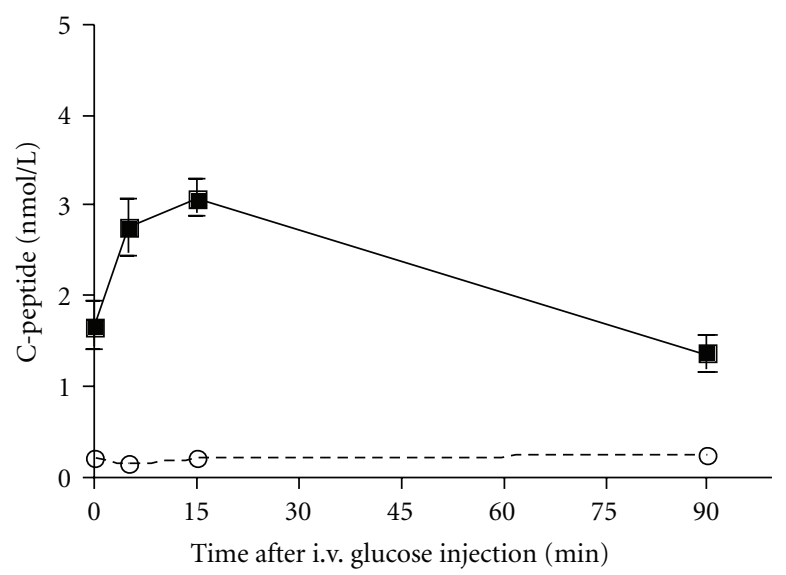

(c)

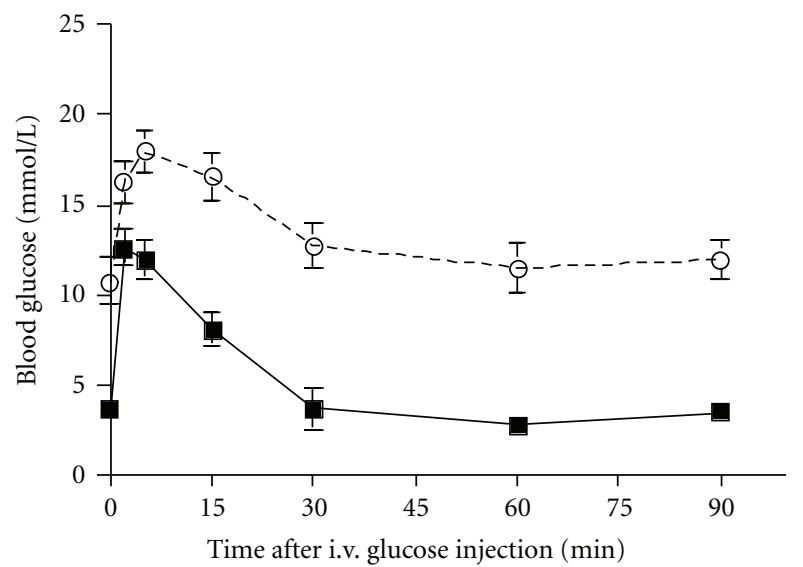

(b)

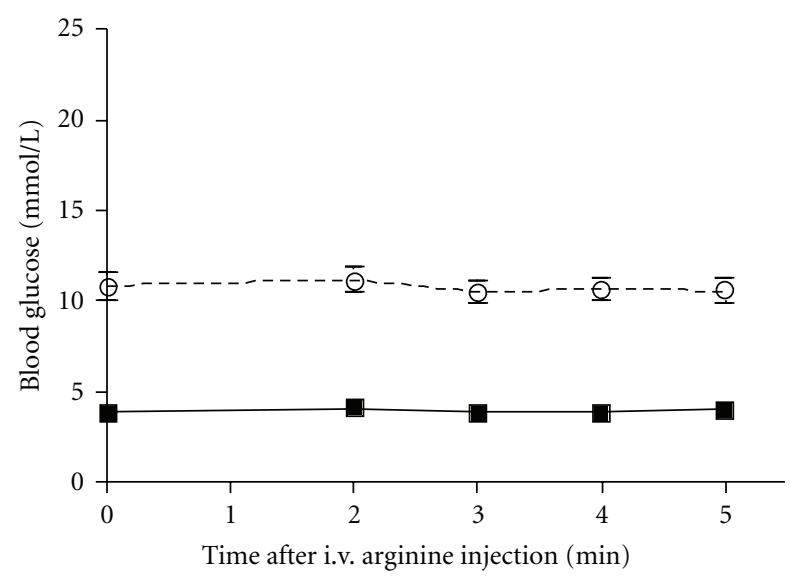

(d)

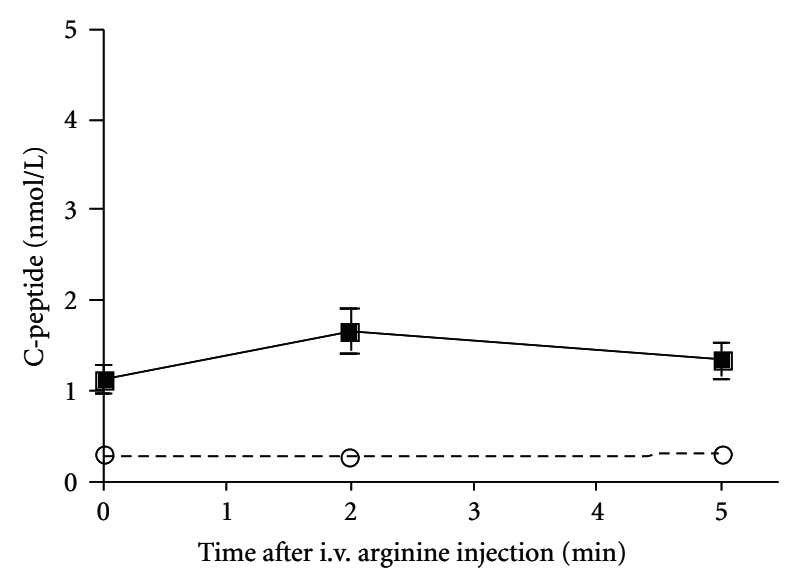

(e)

Figure 1: Comparison of metabolic parameters between nondiabetic and diabetic monkeys. (a) HbAlc comparison between non diabetic NHPs and post-STZ diabetic NHPs $\left({ }^{*} P<.05\right)$. Mean \pm SE of blood glucose levels $(\mathrm{b}, \mathrm{d})$ and primate C-peptide levels $(\mathrm{c}, \mathrm{e})$ during IVGTT $(\mathrm{b}, \mathrm{c})$ and AST (d, e) in nondiabetic (solid lines) and diabetic (broken lines) monkeys. The primate C-peptide response to physiological stimuli was completely abolished in diabetic monkeys. This was associated with a prolonged increase in the blood glucose level.

and HbAlc increased after STZ, as also shown in monkey M124-08, a substantial decrease in blood glucose levels and a drop in the HbAlc level from 9.9\% to 6.5. was recorded as effect of the islet transplantation. Better physiological glycemic control was achieved by the islet transplant and was reflected in the improved $\mathrm{HbAlc}$ values, testifying to a better management of the disease.

In this experiment a total of three monkeys were transplanted with porcine islets in the liver via the portal vein; following the transplant, all of them experienced improved 


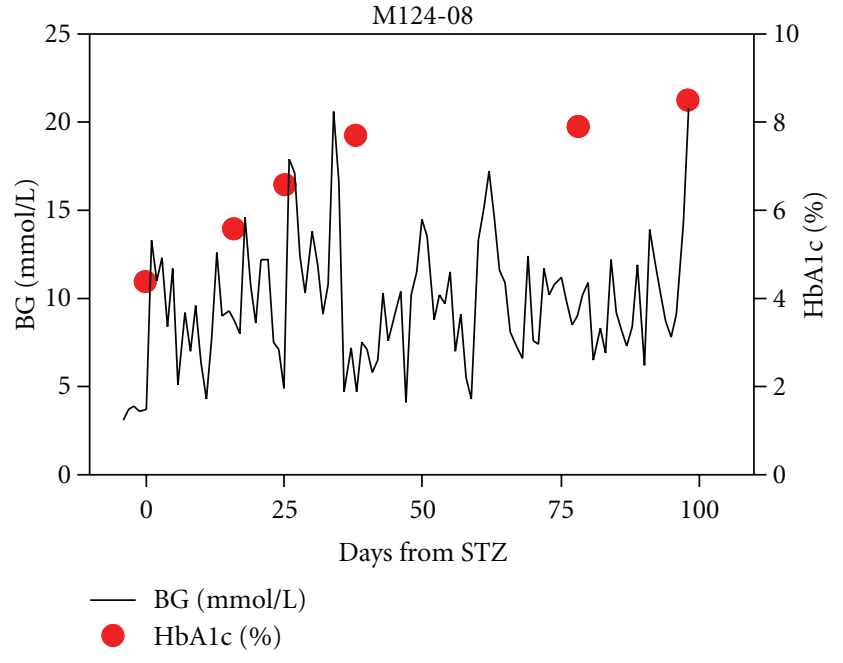

(a)

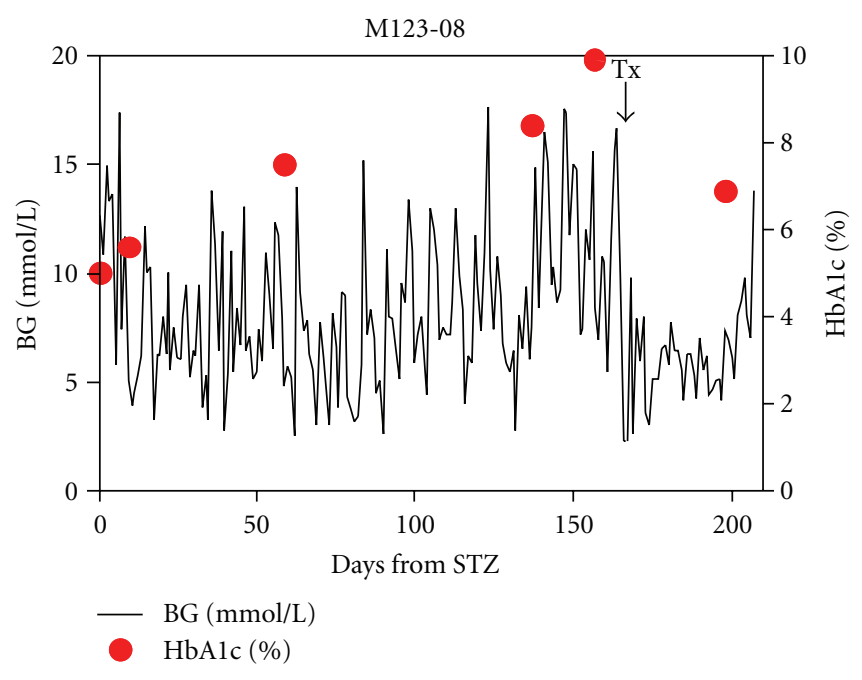

(b)

FIGURE 2: Blood glucose levels (solid lines) and HbA1c (\%) (red dots) in STZ diabetic NHP (a) and STZ diabetic with porcine islet graft NHP (b). In (a) the HbAlc values are increasing overtime despite exogenous insulin treatment; in (b) the HbA1c value drops after porcine islet transplant.

metabolic control of glucose. Improvement was defined by a statistically significant drop in between blood glucose levels $(8.87 \pm 0.19 \mathrm{mmol} / \mathrm{L}$ versus $5.28 \pm 0.06 \mathrm{mmol} / \mathrm{L}$, $P<.0001)$ and insulin dose $\left(1.07 \pm 0.06 \mathrm{IU} \mathrm{Kg}^{-1} \mathrm{day}^{-1}\right.$ versus $\left.0.04 \pm 0.01 \mathrm{IU} \mathrm{Kg}^{-1} \mathrm{day}^{-1}, P<.0001\right)$. Paralleling these parameters, a statistically significant decrease in HbAlc percentage $(8.11 \pm 0.36$ versus $6.16 \pm 0.21, P<.0001)$ was found before and after islet transplantation (Figures 3(a), 3(b), 3(c)).

Figure 4 shows a summary of the-HbAlc values comparing nondiabetic, diabetic, and islet-transplanted NHPs. There is a statistically significant difference in HbAlc levels between nondiabetic and diabetic NHPs and between nondiabetic and islet-transplanted NHPs $(P<.0001)$, showing a trend of improvement of HbAlc values that parallels the improvement of blood glucose levels, as expected. However, caution is needed in interpreting these results because of the short time between samples.

\section{Discussion}

Glycated hemoglobin $(\mathrm{Hb})$ is produced when a carbohydrate, such as glucose, binds to an $\mathrm{Hb}$ molecule, such as $\mathrm{HbA}_{0}$, and undergoes intermolecular transformation to form a stable glycated ketoamine product [23].

$\mathrm{HbAlc}$ is formed via a posttranslational nonenzymatic attachment of glucose to hemoglobin at a rate dependent on the ambient blood glucose during the lifespan of the red blood cells (approximately 120 days in humans). Glycated $\mathrm{Hb}$ percentage represents therefore the integrated value for average blood glucose concentrations in the preceding 6 to 8 weeks [10]. A number of different glycated $\mathrm{Hb}$ forms have been identified, reflecting various attached sugar residues. These forms include HbAla (fructose-1,6-diphosphate, or glucose-6-phosphate), HbA1b (ketamine-linked pyruvic acid), and HbA1c (glucose) [4]. This last form is the most commonly tested, constituting approximately $80 \%$ of hemoglobin A1 (HbA1). This hemoglobin is a derivate of adult hemoglobin (HbA), with monosaccharide (fructose or glucose) attachments. In strict chemical terms, the molecular structure of HbA1c is $\mathrm{N}$-(1-deoxy)-fructosyl-hemoglobin or $\mathrm{N}$-(1-deoxyfroctose-1-yl) hemoglobin beta chain. Methods routinely used for the measurement of glycated $\mathrm{Hb}$ percentage separate the molecule on the basis of its charge, structure, or antigenic properties [10]. The most popular methods rely on the increased negative charge found in the glycated $\mathrm{Hb}$ molecule to distinguish it from its nonglycated form. These assays include electrophoresis and ion-exchange chromatography as by high-performance liquid chromatography (HPLC). Alternatively, boronate affinity chromatography separates glycated $\mathrm{Hb}$ on the basis of its structure rather than its charge. In this assay, separation is the result of carbohydrate moieties on the glycated $\mathrm{Hb}$ molecule binding by condensation to the affinity reagent, di-hydroxyboronate. This method is specific for all glycated $\mathrm{Hbs}$, irrespective of molecular charge or the site of glycation on the $\mathrm{Hb}$ molecule. In addition, it is also able to detect the glycated portion of $\mathrm{Hb}$ in patients with $\mathrm{Hb}$ variants such as $\mathrm{Hb} \mathrm{S}$, $\mathrm{C}$, or $\mathrm{F}$. Thus, the term total glycated $\mathrm{Hb}$ has been used to describe this type of assay. Finally, immunoassays, such as the method we have utilized in this study, have been developed for the measurement of HbAlc. Monoclonal or polyclonal antibodies generated against the 6 - to 8 -amino acid peptide of the glycated amino terminus of the $\beta$-globin chain are here utilized. Advantages to measure HbAlc percentage with this technology involve the simplicity of the approach; the need for one small (only few microliters) blood sample; the fact that the assay is relatively unaffected by recent food intake, activity, illness, or stress; it still reflects glycemic control during the preceding few weeks [10] allowing measurement 


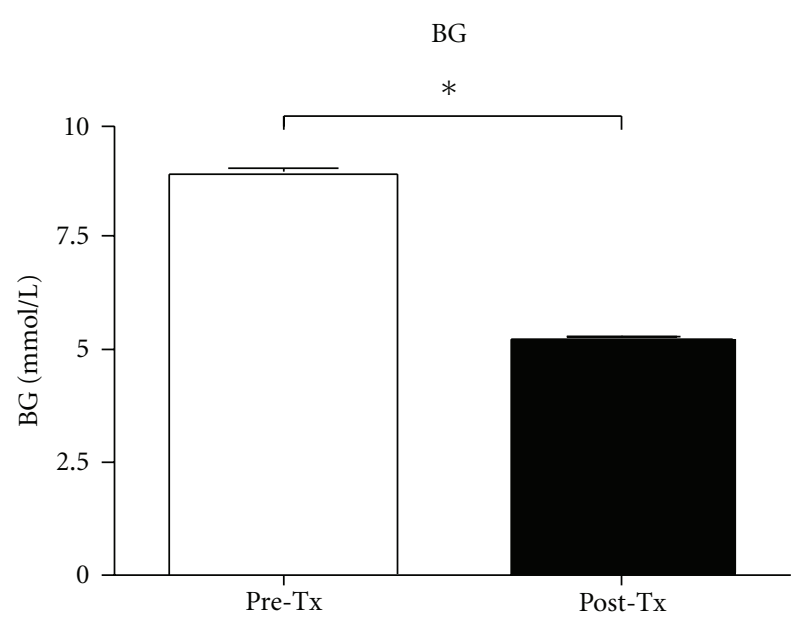

(a)

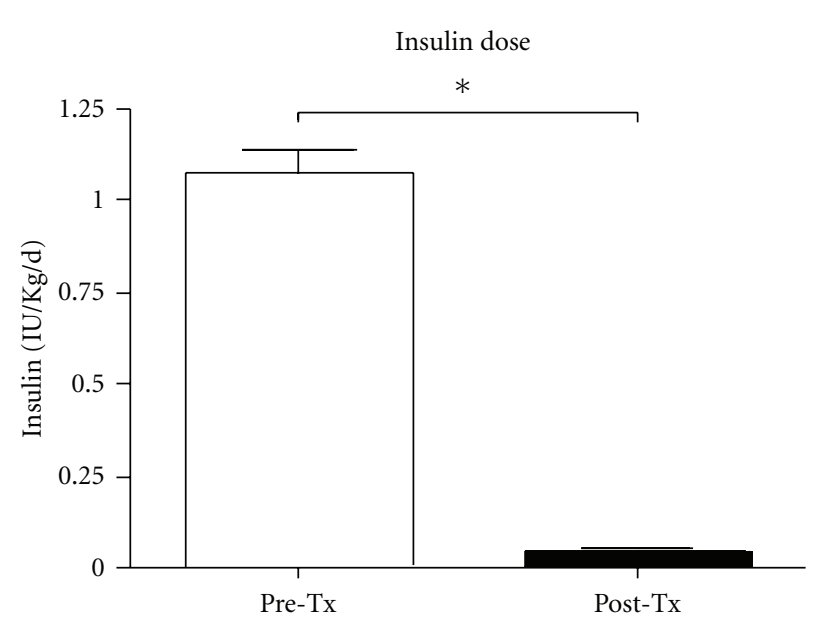

(b)

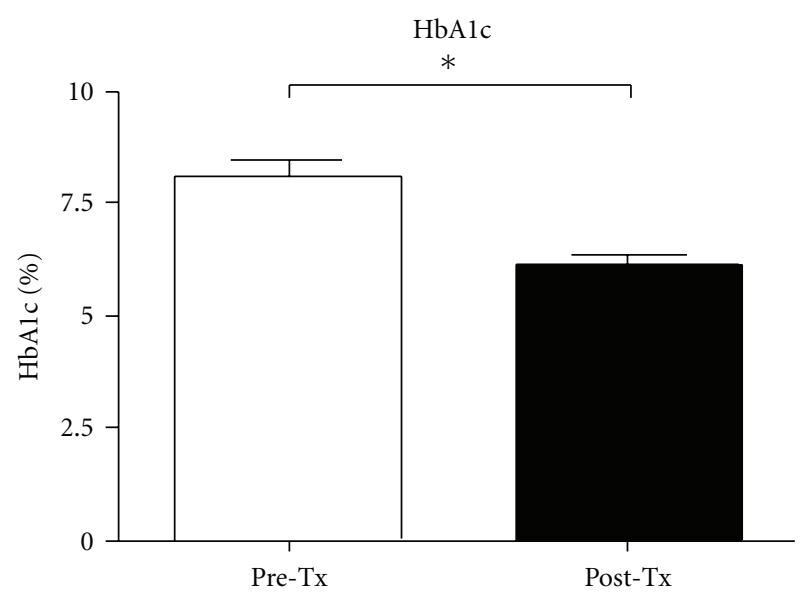

(c)

FIgURE 3: Comparison between blood glucose levels ( $\mathrm{mmol} / \mathrm{L})(\mathrm{a})$, insulin dose (IU kg $\left.{ }^{-1} \mathrm{day}^{-1}\right)(\mathrm{b})$, and HbAlc (\%) (c) in NHPs before and after porcine islet transplantation. There is a statistically significant difference $\left({ }^{*} P<.0001\right)$.

of HbAlc even when pathological hemoglobin variants or NHP hemoglobins are involved. Unfortunately, there are also a lot of different variables associated with measurement of glycated $\mathrm{Hb}$ percentage that could potentially modify those values; for example, processes that decrease the mean lifespan of RBCs will reduce the availability of $\mathrm{Hb}$ for glycation and, therefore, the percentage of glycated $\mathrm{Hb}$, irrespective of glucose concentrations. Similarly, conditions that increase the lifespan of RBCs (e.g., iron deficiency) will increase the amount of glycated $\mathrm{Hb}$. Appropriate validation is therefore required for experimental animal models such as diabetic NHP recipients of pig islet xenotransplantations. Reliable measurement of glycated $\mathrm{Hb}$ percentages would be then useful in determining the efficacy of therapeutic treatments.

Glycated $\mathrm{Hb}$ percentages have been measured, only to a limited degree, in non diabetic, borderline-diabetic, and confirmed-diabetic NHPs [17, 24-26]. These studies have involved a relatively low number of species and various methods. Percentages of $\mathrm{HbAl}$ and $\mathrm{HbA} 1 \mathrm{c}$ in nondiabetic baboons (Papio anubis), measured by use of cation-exchange chromatography, are approximately half of those found in humans [24]. It has been suggested that this may be explained on the basis of differences in the life-span of RBCs in humans (100 to 120 days) compared to baboons (30 to 60 days). Variations may also be related to differences in permeability of RBCs to glucose [17]. At least 2 studies [25, 26] have documented an increase in HbA1c percentages in borderlinediabetic or confirmed-diabetic NHPs. In one group of Celebes crested macaques (Macaca nigra), the HbA1c value increased from $2.6 \%$ in nondiabetic macaques to $7.9 \%$ in diabetic macaques, as measured by use of electrophoresis [25]. In addition macaques without overt hyperglycemia, but with impaired glucose clearance, impaired insulin secretion, and increased postprandial glucose concentrations, had a significant increase in HbAlc content to $3.5 \%$. Reference ranges for glycated $\mathrm{Hb}$ percentages have not been determined in many NHPs, but values that increase by $\geq 10 \%$ were generally considered to be abnormal [7]. Although the number of animals that were evaluated in our study is small, also reflecting the complexity of the experimental model, we had the opportunity to use the same technology to measure variations in $\mathrm{HbAlc}$ values within the same 


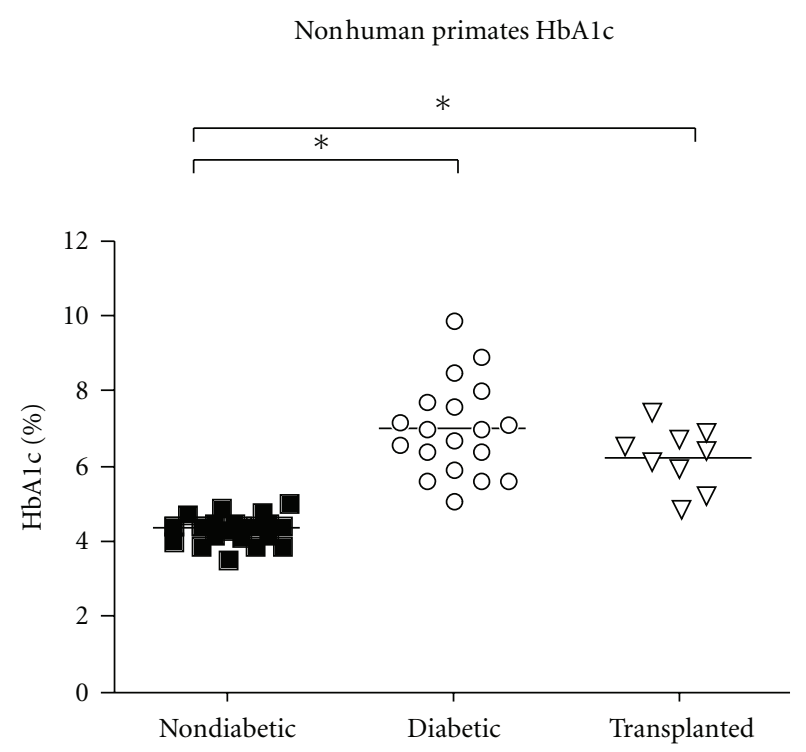

Figure 4: Comparison between HbA1c \% levels in nondiabetic, diabetic, and porcine islet transplanted NHPs. A statistically significant difference is shown between nondiabetic and diabetic animals and nondiabetic and islet transplanted animals $\left({ }^{*} P<.001\right)$.

animals under different clinical metabolic conditions: prior to diabetes induction, as insulin-dependent diabetics, and after islet transplantation.

The levels of HbAlc obtained reflected different glucose metabolic conditions such as diabetes, and improved metabolic control following islet transplantation. These values coherently represent the expected trends relative to the experimental metabolic conditions and further validate the technical approach proposed. By using this simple method in broader scale studies and employing larger numbers of animals, a better correlation between $\mathrm{HbA1c}$ levels and blood glucose levels in Cynomolgus monkeys can be achieved.

\section{Conclusions}

In this study we presented the HbAlc values of nondiabetic and diabetic NHPs (Macaca Fascicularis), analyzed with an inhibition of latex agglutination assay (HbAlc-specific mouse monoclonal antibody adsorbent onto latex particles). These values are lower than the ones we find in humans without diabetes and very similar to those in diabetic patients under insulin treatment, respectively. Total HbA1c percentage can be measured with a user friendly assay and provides useful information for control of diabetes mellitus in NPHs, as is done in human patients, and it could be used during the standard management of glucose metabolism in those animals. Our data provide evidence that $\mathrm{HbAlc}$ can be used to monitor diabetes in streptozotocin-diabetic monkeys and to receive feedbacks on the functionality of xenogenic islet transplantion, particularly useful during long-term followups.

\section{Acknowledgments}

The authors would like to thank Ms. Amber Funair and Ms. Candy Knoll for excellent laboratory assistance and Drs. Noriko Murase, Hidetaka Hara, and Mohamed Ezzelarab, for help in performing pig donor pancreatectomies and islet transplantation. This paper was in part supported by Department of Defense Grant W81XWH-06-1-0317, by JDRF Grant 6-2005-1180.

\section{References}

[1] N. S. Kenyon, M. Chatzipetrou, M. Masetti et al., "Long-term survival and function of intrahepatic islet allografts in rhesus monkeys treated with humanized anti-CD154," Proceedings of the National Academy of Sciences of the United States of America, vol. 96, no. 14, pp. 8132-8137, 1999.

[2] P. P. M. Rood, R. Bottino, A. N. Balamurugan et al., "Induction of diabetes in cynomolgus monkeys with high-dose streptozotocin: adverse effects and early responses," Pancreas, vol. 33, no. 3, pp. 287-292, 2006

[3] H. Shamoon, H. Duffy, N. Fleischer et al., "The effect of intensive treatment of diabetes on the development and progression of long-term complications in insulin-dependent diabetes mellitus," The New England Journal of Medicine, vol. 329, no. 14, pp. 977-986, 1993.

[4] D. B. Sacks, D. E. Bruns, D. E. Goldstein, N. K. Maclaren, J. M. McDonald, and M. Parrott, "Guidelines and recommendations for laboratory analysis in the diagnosis and management of diabetyes mellitus," Clinical Chemistry, vol. 48, no. 3, pp. 436-472, 2002.

[5] A. H. Berg and D. B. Sacks, "Haemoglobin $A_{1 c}$ analysis in the management of patients with diabetes: from chaos to harmony," Journal of Clinical Pathology, vol. 61, no. 9, pp. 983987, 2008.

[6] R. Turner, "Intensive blood-glucose control with sulphonylureas or insulin compared with conventional treatment and risk of complications in patients with type 2 diabetes (UKPDS 33)," The Lancet, vol. 352, no. 9131, pp. 837-853, 1998.

[7] C. Walzer, "Diabetes in primates," in Zoo and Wild Animal Medicine. Current Therapy 4, M. E. Fowler and R. E. Miller, Eds., pp. 397-400, WB Saunders, Philadelphia, Pa, USA, 1998.

[8] C. A. Burtis and E. R. Ashwood, "Carbohydrates," in Tietz Textbook of Clinical Chemistry, C. A. Burtis and E. R. Ashwood, Eds., pp. 750-808, WB Saunders, Philadelphia, Pa, USA, 3rd edition, 1999.

[9] W. T. Cefalu, J. D. Wagner, and A. D. Bell-Farrow, "Role of glycated proteins in detecting and monitoring diabetes in cynomolgus monkeys," Laboratory Animal Science, vol. 43, no. 1, pp. 73-77, 1993.

[10] E. S. Kilpatrick, "Problems in the assessment of glycaemic control in diabetes mellitus," Diabetic Medicine, vol. 14, no. 10, pp. 819-831, 1997.

[11] J. D. Wagner, J. D. Bagdade, K. N. Litwak et al., "Increased glycation of plasma lipoproteins in diabetic cynomolgus monkeys," Laboratory Animal Science, vol. 46, no. 1, pp. 3135, 1996

[12] R. Kahn, "Report of the expert committee on the diagnosis and classification of diabetes mellitus," Diabetes Care, vol. 20, no. 7, pp. 1183-1197, 1997.

[13] World Health Organization, "WHO expert committee on diabetes mellitus. Second report,” Tech Rep Ser 646:8-12, 1980. 
[14] World Health Organization, "Diabetes mellitus: report of a WHO Study Group," Tech Rep Ser 727, 1985.

[15] C. F. Howard and M. Yasuda, "Diabetes mellitus in nonhuman primates: recent research advances and current husbandry practices," Journal of Medical Primatology, vol. 19, no. 7, pp. 609-625, 1990.

[16] J. K. Kemnitz, A. Baker, and W. Shellabarger, "Glucose tolerance and insulin levels of captive orangutans," in Proceedings of the International Conference on Orangutans: The Neglected Ape, J. J. Ogden, L. A. Perkins, and L. Sheeran, Eds., pp. 250256, Zoological Society of San Diego, San Diego, Calif, USA, 1994.

[17] N. A. Richter, "Percentage of glycosylated hemoglobin and serum concentration of glucose in the blood of Japanese macaques and in three exotic ruminant species," American Journal of Veterinary Research, vol. 47, no. 8, pp. 1783-1784, 1986.

[18] A. Casu, R. Bottino, A. N. Balamurugan et al., "Metabolic aspects of pig-to-monkey (Macaca fascicularis) islet transplantation: implications for translation into clinical practice," Diabetologia, vol. 51, no. 1, pp. 120-129, 2008.

[19] R. Bottino, A. N. Balamurugan, C. Smetanka et al., "Isolation outcome and functional characteristics of young and adult pig pancreatic islets for transplantation studies," Xenotransplantation, vol. 14, no. 1, pp. 74-82, 2007.

[20] F. S. Greenspan and D. G. Gardner, "Normal hormone reference ranges," in Basic and Clinical Endocrinology, F. S. Greenspan and D. G. Gardner, Eds., pp. 925-926, McGrawHill, New York, NY, USA, 7th edition, 2004.

[21] S. Genuth, K. G. Alberti, P. Bennett et al., "Follow-up report on the diagnosis of diabetes mellitus," Diabetes Care, vol. 26, no. 11, pp. 3160-3167, 2003.

[22] J. B. Saaddine, A. Fagot-Campagna, D. Rolka et al., "Distribution of HbA levels for children and young adults in the U.S.: third national health and nutrition examination survey," Diabetes Care, vol. 25, no. 8, pp. 1326-1330, 2002.

[23] W. Huisman, J. P. A. A. Kuijken, H. L. Tan-Tjiong, E. P. Duurkoop, and B. Leijnse, "Unstable glycosylated hemoglobin in patients with diabetes mellitus," Clinica Chimica Acta, vol. 118, no. 2-3, pp. 303-309, 1982.

[24] J. B. Alperin, P. A. Dow, and L. C. Stout, "A comparison of hemoglobin $\mathrm{A}_{\mathrm{lc}}$ in human and baboon blood," Acta Haematologica, vol. 61, no. 6, pp. 334-338, 1979.

[25] C. F. Howard, "Correlations of hemoglobin $A_{1 c}$ and metabolic status in nondiabetic, borderline diabetic, and diabetic Macaca nigra," Diabetes, vol. 31, no. 12, pp. 1105-1108, 1982.

[26] J. A. Widness, R. Schwartz, and D. Thompson, "Hemoglobin $A_{1 c}$ in the glucose-intolerant, streptozotocin-treated or pancreatectomized macaque monkey," Diabetes, vol. 27, no. 12, pp. 1182-1188, 1978. 


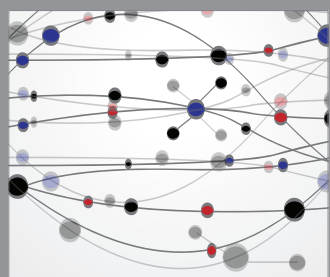

The Scientific World Journal
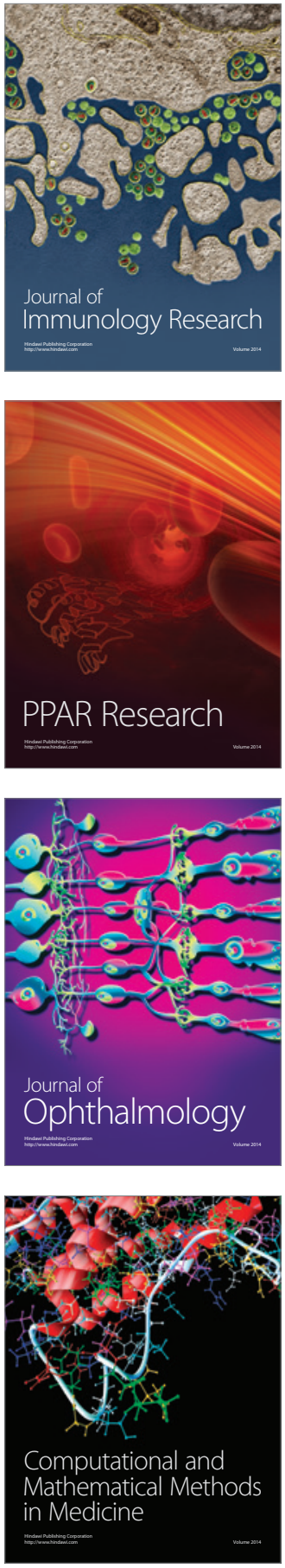

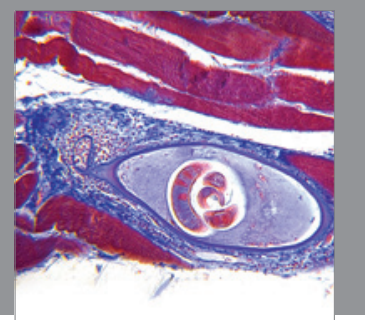

Gastroenterology

Research and Practice
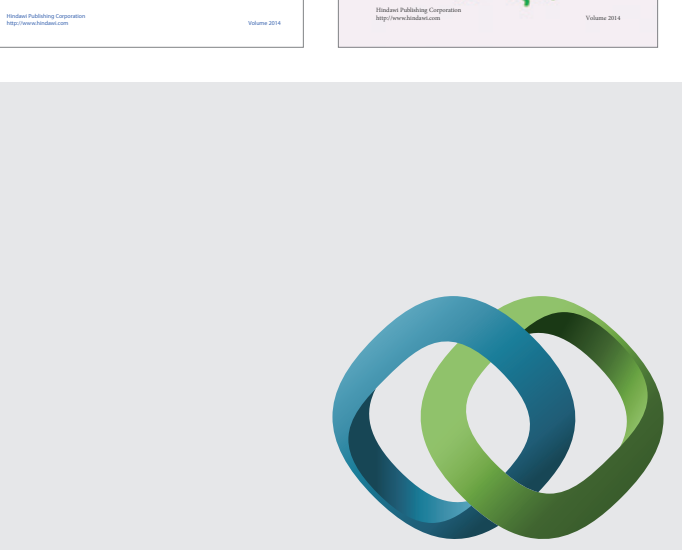

\section{Hindawi}

Submit your manuscripts at

http://www.hindawi.com
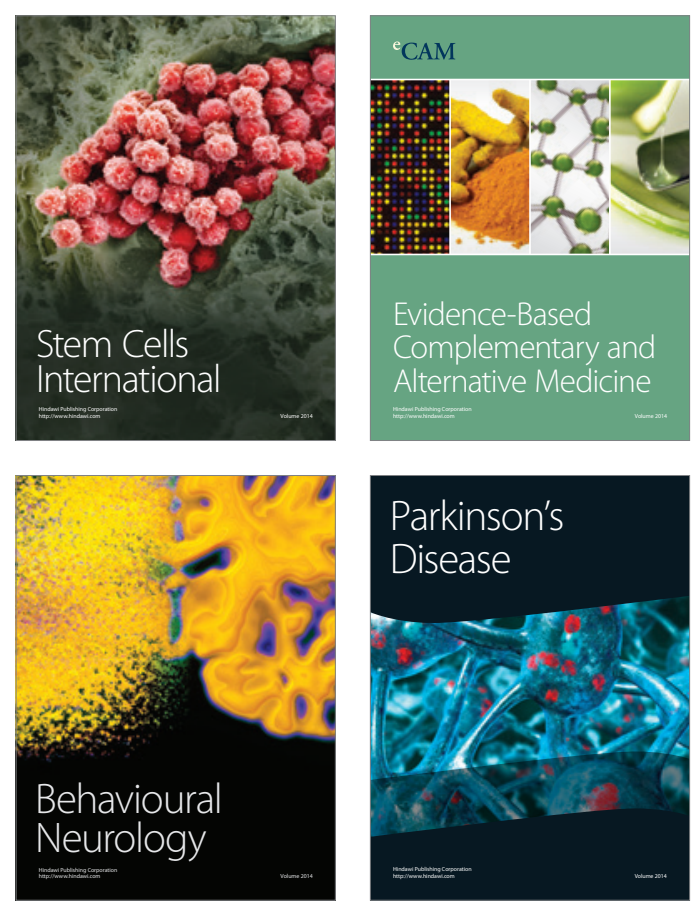

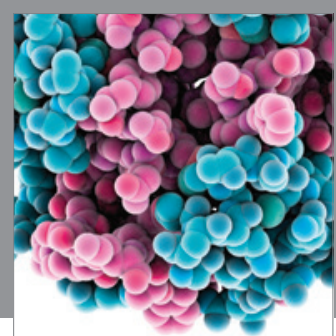

Journal of
Diabetes Research

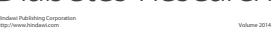

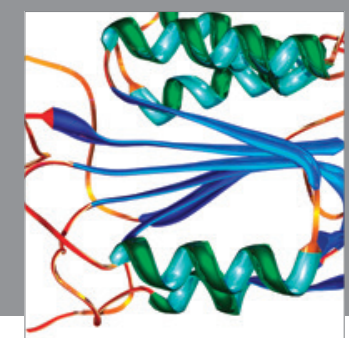

Disease Markers
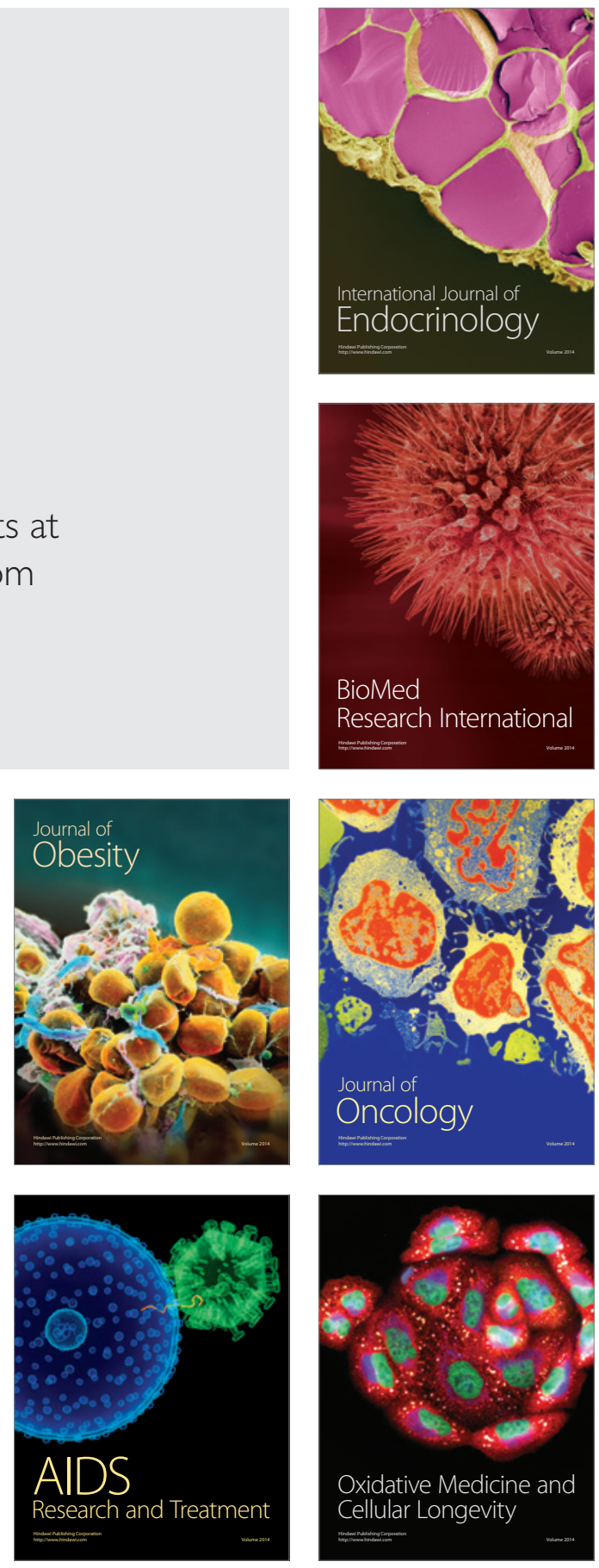